\title{
Impacto por COVID-19 en Ecuador y planteamiento de una propuesta de política pública de prevención @®(
}

Impact of COVID-19 in Ecuador and proposal of a public prevention

policy proposal

Verónica Gabriela López Ullauri. ${ }^{1}$, Marco Eduardo Chasipanta Avalos. ${ }^{2}$, Adriana

Elizabeth Campoverde Ávila. ${ }^{3} \&$ Luis Eduardo Pavón Rosero. ${ }^{4}$

DOI: https://doi.org/10.33262/anatomiadigital.v4i4.1911

\begin{abstract}
.
Introduction, the emergence of a new infectious disease is always a complex situation, especially if it presents itself as an epidemic or pandemic of significant extent or severity, sarcov-2 later called covid-19 has had a significant impact on all economies. Objective: to expose the costs of the disease in its different stages of evolution and establish a clear
\end{abstract}

\section{Resumen.}

Introducción. La aparición de una nueva enfermedad infecciosa supone siempre una situación compleja, especialmente si lo hace como una epidemia o pandemias de extensión o gravedad significativas, el SarCov-2 luego llamado COVID-19 ha sido un impacto significativo en todas las economías. Objetivo: exponer los costos de la enfermedad en sus diferentes fases

\footnotetext{
1 Escuela Superior Politécnica de Chimborazo, Facultad de Salud Pública, Riobamba, Ecuador. verónicag.lopez@espoch.edu.ec, ORCID https://orcid.org/0000-0001-6505-5166

${ }^{2}$ Hospital General San Juan, MSc. (c) Seguridad y Salud Ocupacional, marco.chasipanta@hotmail.es, ORCID: https://orcid.org/0000-0002-9466-681X

3 Hospital IESS Carlos Andrade Marín, MSc. Gerencia en Instituciones de Salud, Quito, Ecuador. aeca2811@icloud.com, (D) ORCID https://orcid.org/0000-0001-7878-1917

${ }^{4}$ Universidad de las Américas, PhD. Gobernanza y Gestión Pública, Quito, luis.pavon@udla.edu.ec, ORCID: https://orcid.org/0000-0002-4761-0397
} 
prevention policy that makes us reflect on the emotional, psychological and economic consequences that this disease generated in its initial stages. Methodology. The research design was analytical-descriptive, cataloged as a field study, the methodology used was inductive deductive, in which information gathering techniques and surveys were selected and applied, which allowed the development of hypotheses: ¿a public policy of prevention? Of covid-19, will it allow the reduction of state spending? Is the cost of prevention lower than the cost of treating covid-19? In addition to carrying out the technical and statistical analysis of the patients in their different periods of evolution and the economic impact that these generate in each of the stages. Results. Asymptomatic and mild symptomatic: the costs represent 80.29 USD in a total of 14 days. Moderate symptomatic: cost per hospital stay per day 1465.76 USD in public hospitals and 1805.82 USD in private hospitals. Severe symptomatic: cost per hospital stay per day 1722.87 USD in public hospitals and 2122.58 USD in private hospitals. Conclusions: The limited economic capacity of the health systems exceeded the supply of both public and private hospitals with high costs that exceeded the economic capacity of the users; Strategic preventive models and inspection controls must be established as a public preventive measure for an adequate use of health resources.

Keywords: pandemic, covid-19, health, costs, hospitals. de evolución y establecer una política clara de prevención que haga reflexionar las consecuencias emocionales, psicológicas y económicas que generó esta enfermedad en sus etapas iniciales. Metodología. El diseño de investigación fue analítico-descriptivo, catalogado como un estudio de campo, la metodología utilizada fue inductivo deductivo, en la cual se seleccionó y aplicó técnicas de recolección de información, encuestas, que nos permitió desarrollar hipótesis: ¿Una política pública de prevención de COVID-19, permitirá la reducción de los gastos estatales? ¿Es inferior el costo de prevención frente al costo de tratamiento del COVID-19? Además de realizar el análisis técnico y estadístico de los enfermos en sus diferentes periodos de evolución y el impacto económico que éstos generan en cada uno de los estadios. Resultados. Asintomático y sintomático leve: los costos representan 80.29 USD en un total de 14 días. Sintomático moderado: costo por estancia hospitalaria por día 1465,76 USD en hospitales públicos y 1805,82 USD en hospitales privados. Sintomático grave: costo por estancia hospitalaria por día 1722,87 USD en hospitales públicos y 2122,58 USD en hospitales privados. Conclusiones. La limitada capacidad económica de los sistemas de salud supero el abastecimiento de los centros hospitalarios tanto públicos como privados con costos elevados que superaban la capacidad económica de los usuarios; se debe establecer modelos estratégicos preventivos y controles de fiscalización como medida preventiva pública para un adecuado uso de los recursos en salud. 
Palabras Claves: Pandemia, COVID-19, salud, Costos, Hospitales.

\section{Introducción}

La aparición de una nueva enfermedad infecciosa supone siempre una situación compleja, especialmente si lo hace como una epidemia o pandemias de extensión o gravedad significativas, el SarCov-2 luego llamado COVID-19 ha sido un impacto significativo en todas las economías. Los casos aumentaron rápidamente en Wuhan y en la provincia de Hubei, extendiéndose en menor número y con cadenas de transmisión ilimitadas con casos importados a nivel mundial, El 30 de enero de 2020 la OMS declaró esta epidemia como una Emergencia de Salud Pública de Interés Internacional. (Organización Panamericana de Salud / Organización Mundial de la Salud, 2020). El virus COVID-19 está relacionado con otros coronavirus que circulan entre los murciélagos (incluyendo el SARS coronavirus), el salto ocasional de un virus de un animal al hombre (spillover) es habitual entre los coronavirus; es así, sucedió con el SARS en 2002-2003 y con el MERS desde 2012. Está demostrado que el COVID-19 se transmite de forma eficiente de persona a persona, habiéndose identificado agrupaciones de casos intrafamiliares y de transmisión a personal sanitario, la vía de transmisión del COVID-19 es por contacto y gotas respiratorias (aerosoles), en distancias cortas (1,5 m) y también por fómites contaminados por dichos aerosoles (MINISTERIO DE SANIDAD, 2020).

Con 10,93 muertes por millón de personas por coronavirus 2019 (COVID-19), al 6 de abril de 2020, Ecuador tiene una de las tasas más altas de mortalidad por COVID-19 en América Latina. Con solo 7,46 pruebas de PCR por 10.000 personas, el gobierno tiene una necesidad crítica de un mecanismo sistemático para reforzar la autoevaluación, el rastreo de contactos y el aislamiento efectivo de los casos sospechosos durante el primer y segundo trimestre del 2020, con una política pública de salud en decadencia que denota las necesidades de este sector (Chauca, 2021; Cioti et al., 2020). El Ministerio de Salud Pública del Ecuador, se centró en cerrar las brechas en los recursos médicos aumentando la disponibilidad de equipos de protección personal, camas de hospital y tratando de remediar la sobrecarga de las instalaciones de atención médica así como los servicios mortuorios en la provincia de Guayas, el principal foco del brote del país durante el 2020, dado el bajo número de personas examinadas (13.039 examinadas en un país con 17.47 millones de personas). El bloqueo de 23 días se ha aplicado de manera desigual, haciendo que la autoevaluación y el seguimiento de casos sean un desafío, especialmente para las personas desfavorecidas, como las poblaciones indígenas y los más de 350.000 refugiados venezolanos (Ortiz et al., 2020).

Ecuador carece de cobertura médica universal sin registros médicos a los que se pueda acceder virtualmente a través de proveedores públicos y privados. Sin embargo, el país tiene capacidad, desde organizaciones de la sociedad civil, oficinas políticas locales e instituciones públicas con conocimiento o contacto con sus comunidades, estas estructuras multisectoriales locales ayudaron a adoptar una estrategia modular de pruebas e información que mejoró la movilidad innecesaria e incrementó la necesidad sobre las 
instalaciones de atención médica (Molina \& Mejias, 2020; Programa de las Naciones Unidas para el Desarrollo, 2020).

Los centros de salud agregarían datos para mejorar el modelado epidemiológico y brindarían apoyo especializado. Cuando la incidencia de la infección es baja, los grupos potenciales ya deberían comenzar a trabajar, convocando a las partes interesadas locales para evaluar los activos sociales existentes y el apoyo potencial del sistema de salud en general (Sedano-Chiroque et al., 2020).

Hasta el primer semestre del 2020 ninguna de las entidades de gobierno relacionada con temas de salud ha transparentado las cifras reales de enfermos ni tampoco se ha realizado un estudio de los costos que implica esta enfermedad en cada una de las fases de evolución, es por ello que la presente investigación retrospectiva pretende exponer los costos de la enfermedad en sus diferentes fases de evolución y establecer una política clara de prevención que haga reflexionar las consecuencias emocionales, psicológicas y económicas que generó esta enfermedad en sus etapas iniciales, con una crisis económica, aumento de costos en los insumos, escases de medicamentos y un sistema de salud público ineficaz.

\section{Marco teórico}

Los coronavirus son una extensa familia de virus que pueden causar enfermedades tanto en animales como en humanos. En los humanos, se sabe que varios coronavirus causan infecciones respiratorias que pueden ir desde el resfriado común hasta enfermedades más graves como el síndrome respiratorio de Oriente Medio (MERS), el síndrome agudo respiratorio severo (SARS) y la enfermedad por coronavirus 2019 (COVID 19), causante de la pandemia que se atravesó durante el año 2020 y se mantiene hasta la actualidad.

El COVID-19 es originado por el virus SARs-CoV-2 el mismo que se trasfiere de persona a persona a través de fómites o aerosoles respiratorios, en un medio ambiente contiguo de la persona infectada. Esta enfermedad fue declara por la OMS como pandemia en marzo de 2020 (Organización Mundial de la Salud, 2020).

El brote de COVID-19 se propagó en poco tiempo, desarrollando características como: la transmisión rápida y peligrosa que ha limitado la capacidad resolutiva de los sistemas de salud, la letalidad incrementa en grupos de edad avanzada con ciertas comorbilidades; así como las consecuencias socioeconómicas que se han presentado debido a los trastornos sanitarios y medidas tomadas para contralar la trasmisión (Organización Mundial de la Salud, 2020).

COVID-19 presenta manifestaciones clínicas variadas, que pueden ir desde infecciones asintomáticas hasta cuadros severos que pueden ocasionar la muerte. De la experiencia obtenida del brote en China, el $80 \%$ de los casos presentó sintomatología leve o moderada (que incluye casos sin neumonía o de neumonía leve); el 13.8\% presentó un cuadro grave y un $6.1 \%$ fueron casos críticos, los cuales pueden manifestarse de formas diversas, como 
neumonía grave, Síndrome de Dificultad Respiratoria Aguda (SDRA), choque séptico, respuesta inflamatoria excesiva, entre otros (MINISTERIO DE SANIDAD, 2020).

En el Ecuador la pandemia por COVID-19 está exigiendo un alto precio a personas, familias, comunidades y sociedades. Hasta agosto del 2020, se han reportado 102941 casos positivos, con 6105 personas fallecidas, según estos datos oficiales, la letalidad en el país fue de $5.9 \%$ (Bajaña, 2020).

Los principales deterioros clínicos que representan un ingreso a terapia intensiva con la necesidad de una ventilación mecánica, se puede producir a partir de la segunda semana de presentar la enfermedad, con una instancia hospitalaria que puede oscilar entre los 5 a 28 días dependiendo del estado general y las comorbilidades del paciente (Velez-Paez et al., 2021).

El incremento de la tasa de casos positivos de Covid-19 en el Ecuador en el primer semestre del 2020 fue de $10.94 \%$ por cada 100.000 habitantes siendo uno de las tasas más elevadas a nivel mundial. Esto también se refleja en la tasa de letalidad que se obtuvo en el primer semestre del 2020 siendo de 7,33\% una de las más altas a nivel de Sudamérica (Inca-Ruiz \& Inca-Leon, 2020).

Todo esto demanda una mejor comprensión de los costos potenciales que plantea la atención de los pacientes contagiados de COVID-19 al sistema de salud. Un estudio realizado en Estados Unidos indica que en dicho país el costo medio de un paciente sintomático es de 3,045 USD; no se dispone este tipo de datos en Ecuador, razón por la que se plantea este estudio, con miras a obtener luces que desvelen la situación actual, lo que permitirá tener una mejor idea del costo que la pandemia representará para el país.

\section{Metodología}

En el estudio, se realizó un diseño analítico-descriptivo y se encuadró en los conceptos paradigmáticos, catalogado como un estudio de campo, la metodología utilizada fue inductivo deductivo.

Para la investigación se seleccionó y aplicó técnicas de recolección de información, que serán las más adecuadas en base a las circunstancias propias de cada institución de salud, que permita la obtención de información suficiente y pertinente, con el fin de sustentar los resultados de este estudio. Adicionalmente, se aplicó la técnica de la encuesta, que fue un cuestionario estructurado con preguntas cerradas, que permitió recopilar información relevante sobre la situación actual de las unidades médicas relacionadas con los protocolos aplicados con los enfermos de COVID-19.

Dentro de la investigación, se plantearon las siguientes hipótesis: ¿Una política pública de prevención de COVID-19, permitirá la reducción de los gastos estatales? ¿Es inferior el costo de prevención frente al costo de tratamiento del COVID-19? 
En el estudio, se consideró realizar el análisis técnico y estadístico de los enfermos en sus diferentes periodos de evolución y el impacto económico que éstos generan en cada uno de los estadios.

\section{Resultados}

Asintomático y sintomático leve: que representan el $83 \%$ con enfermedad, los costos representan 80.29 USD en un total de 14 días, explicado cada uno de los materiales e insumos en la tabla 1.

Tabla 1

Insumos y costos en pacientes asintomáticos

\begin{tabular}{lcccccc}
\hline $\begin{array}{c}\text { TIPO DE } \\
\text { MASCARILLA }\end{array}$ & $\begin{array}{c}\text { \# DE } \\
\text { MASCARILLAS } \\
\text { A UTILIZAR }\end{array}$ & $\begin{array}{c}\text { COSTO DE LA } \\
\text { MASCARILLA }\end{array}$ & JABON & CLORO & $\begin{array}{c}\text { 2 PRUEBAS } \\
\text { RÁPIDAS \$30 c/u }\end{array}$ & TOTAL \\
\hline QUIRÚRGICA & 28 & 0,56 & 1 & 3,61 & 60 & 80.29 \\
KN95 & 14 & 1,3 & 1 & 3,61 & 60 & 82.81 \\
FPP2 & 14 & 3,4 & 1 & 3,61 & 60 & 112,21 \\
N95 & 14 & 9,5 & 1 & 3,61 & 60 & 197,61 \\
\hline
\end{tabular}

Sintomático moderado representando del 13 al 16\%; costo por estancia hospitalaria por día 1465,76usd en hospitales públicos y 1805,82usd en hospitales privados, por tiempo de evolución de 14 días, por un costo de 5781,62 USD en hospitales públicos y 7122,96 USD en hospitales privados, por tiempo de evolución de 21 días, por un costo de 7420,50 USD en hospitales públicos y 9142,06 USD en hospitales privados, por un tiempo de evolución de 28 días, por un costo de 9285,72 USD en hospitales públicos y 11440,01 USD en hospitales privados detallado en la tabla 2.

Tabla 2

Tratamiento pacientes no invasivos

\begin{tabular}{lrrrr}
\hline \multicolumn{1}{c}{ HOSPEDAJE } & \multicolumn{1}{c}{ DIA } & \multicolumn{1}{c}{$\mathbf{1 4}$} & $\mathbf{2 1}$ & $\mathbf{2 8}$ \\
\hline HABITACIÓN INDIVIDUAL. INSTITUCIONES SEGUNDO NIVEL & 55,68 & 779,52 & 1169,28 & 1559,04 \\
CUIDADO Y MANEJO DIARIO. INSTITUCIONES DE SEGUNDO NIVEL & 8,91 & 124,74 & 187,11 & 249,48 \\
DESAYUNO. INSTITUCIONES DE PRIMER Y SEGUNDO NIVEL & 2,28 & 31,92 & 47,88 & 63,84 \\
ALMUERZO. INSTITUCIONES DE PRIMER Y SEGUNDO NIVEL & 4,56 & 63,84 & 95,76 & 127,68 \\
MERIENDA. INSTITUCIONES DE PRIMER Y SEGUNDO NIVEL & 4,56 & 63,84 & 95,76 & 127,68 \\
PROCEDIMIENTOS DE MONITOREO & & & & \\
CONTROL DE PRESIÓN ARTERIAL & 0,54 & 7,56 & 11,34 & 15,12 \\
CONTROL DE SIGNOS VITALES & 1,34 & 18,76 & 28,14 & 37,52 \\
INYECCIÓN INTRAMUSCULAR & 0,74 & 10,36 & 15,54 & 20,72 \\
INYECCIÓN INTRAVENOSA & 0,94 & 13,16 & 19,74 & 26,32 \\
CONTROL DE GLUCOSA CON TIRILLA & 0,8 & 11,2 & 16,8 & 22,4 \\
CAMBIO SONDA VESICAL & 2,81 & 39,34 & 59,01 & 78,68 \\
ADMINISTRACIÓN DE SOLUCIONES INTRAVENOSAS & 0,8 & 11,2 & 16,8 & 22,4 \\
INYECCIONES SUBCUTÁNEAS & 0,74 & 10,36 & 15,54 & 20,72 \\
\hline
\end{tabular}


Tabla 2

Tratamiento pacientes no invasivos (continuación)

\begin{tabular}{|c|c|c|c|c|}
\hline HOSPEDAJE & DIA & 14 & 21 & 28 \\
\hline $\begin{array}{l}\text { ELECTROCARDIOGRAMA, } 12 \text { DERIVACIONES, DE RUTINA, CON } \\
\text { INTERPRETACIÓN Y REPORTE. }\end{array}$ & 23,94 & 335,16 & 502,74 & 670,32 \\
\hline LABORATORIO CLINICO & TOMA & & & \\
\hline HIV $1+2$ & 8,38 & & & \\
\hline PCR CUANTITATIVO ULTRASENSIBLE & 9,44 & 18,88 & 37,76 & 75,52 \\
\hline CORTISOL & 14,1 & & & \\
\hline PROCALCITONINA LAB. CLINICO & 28,5 & & & 28,5 \\
\hline BIOMETRIA HEMATICA+VSG & 4,16 & 8,32 & 16,64 & 33,28 \\
\hline CALCULO DE PLAQUETAS & 3,04 & 6,08 & & \\
\hline CONTAJE DE RETICULOCITOS & 3,35 & & & \\
\hline DIMERO-D & 33,47 & 66,94 & 133,88 & 267,76 \\
\hline FERRITINA & 9,13 & 18,26 & 36,52 & \\
\hline FIBRINOGENO & 8,51 & 17,02 & 34,04 & \\
\hline TIEMPO DE PROTROMBINA (TP) & 3,6 & 7,2 & 14,4 & 28,8 \\
\hline TIEMPO DE TROMBOPLASTINA (TTP) & 3,6 & 7,2 & 14,4 & 28,8 \\
\hline CREATININA & 3,48 & 6,96 & 13,92 & 27,84 \\
\hline ELECTROLITOS NA- K - CL EN SUERO O SANGRE TOTAL & 6,09 & 12,18 & 24,36 & 48,72 \\
\hline FOSFATASA-ALKALINA & 3,23 & 6,46 & & \\
\hline GLUCOSA & 1,93 & 3,86 & 7,72 & 15,44 \\
\hline LDH (DESHIDROGENASA LACTICA) & 3,42 & 6,84 & 13,68 & 27,36 \\
\hline NITROGENO UREICO (BUN) /UREA & 2,42 & 4,84 & 9,68 & \\
\hline TRIGLICERIDOS & 2,55 & 5,1 & & \\
\hline TROPONINA T & 17,7 & & & \\
\hline CK-MB & 14,35 & & & \\
\hline $\mathrm{CPK}$ & 8,07 & & & \\
\hline EMO (UROANALISIS DE RUTINA) & 3,23 & 6,46 & & \\
\hline COVID -19 PRUEBA CUANTITATIVA & 43,38 & 86,76 & 130,14 & \\
\hline COVID - 19 RT-PCR & 120 & 240 & & \\
\hline \multicolumn{5}{|l|}{ IMAGENOLOGIA } \\
\hline EXAMEN RADIOLÓGICO, TÓRAX; POSICIÓN ÚNICA, FRONTAL & 16,46 & 32,92 & 49,38 & \\
\hline $\begin{array}{l}\text { TOMOGRAFÍA AXIAL COMPUTADORIZADA, TÓRAX; SIN MATERIAL } \\
\text { DE CONTRASTE }\end{array}$ & 72,16 & 144,32 & & \\
\hline ECOGRAFÍA RENAL & 25,15 & & & \\
\hline \multicolumn{5}{|l|}{ PROCEDIMIENTOS DE REHABILITACIÓN } \\
\hline $\begin{array}{l}\text { TERAPIA RESPIRATORIA (COBRAR POR SEPARADO USO DE } \\
\text { OXÍGENO) }\end{array}$ & 5,9 & 82,6 & 123,9 & 165,2 \\
\hline \multicolumn{5}{|l|}{ HONORARIOS MEDICOS } \\
\hline $\begin{array}{l}\text { Cuidado hospitalario inicial, por día, para evaluación y manejo de un paciente } \\
\text { que requiere de estos tres componentes: } 1 \text {-- historia clínica completa, 2.- examen } \\
\text { físico completo, 3.- decisiones médicas de moderada complejidad, usualmente, el } \\
\text { problema por el cual el paciente ha sido hospitalizado es de moderada severidad. } \\
\text { El médico consume } 50 \text { minutos en la habitación. }\end{array}$ & 32,34 & & & \\
\hline $\begin{array}{l}\text { Cuidado subsecuente por día para evaluación y manejo de un paciente que } \\
\text { incluye admisión y alta el mismo día, que requiere de estos tres componentes: 1.- } \\
\text { historia clínica completa } 2 .- \text { examen físico completo } 3 \text {-- decisión médica de } \\
\text { moderada complejidad. Consejo y/o coordinación con otros profesionales de } \\
\text { acuerdo a la naturaleza del problema y con las necesidades del paciente y/o su } \\
\text { familia. Tiempo } 25 \text { minutos. }\end{array}$ & 20,11 & 281,54 & 422,31 & 563,08 \\
\hline
\end{tabular}




\section{Tabla 2}

\section{Tratamiento pacientes no invasivos (continuación)}

\begin{tabular}{|c|c|c|c|c|}
\hline HOSPEDAJE & DIA & 14 & 21 & 28 \\
\hline $\begin{array}{l}\text { Interconsulta consulta inicial para un nuevo paciente que requiere de estos tres } \\
\text { componentes. historia focalizada-expandida del problema- examen físico } \\
\text { focalizado expandido } \text { decisión médica de baja complejidad usualmente, el } \\
\text { problema es de baja severidad. El médico pasa aproximadamente } 40 \text { minutos en } \\
\text { la habitación y piso }\end{array}$ & 23,79 & 142,74 & & \\
\hline $\begin{array}{l}\text { Cuidado intermedio adultos evaluación y manejo de un paciente con enfermedad } \\
\text { crítica o un paciente traumatizado crítico, durante los primeros } 30 \text { a } 74 \text { minutos } \\
\text { por día. }\end{array}$ & 41,16 & & & \\
\hline $\begin{array}{l}\text { Adicional al anterior por cada } 30 \text { minutos, su aplicación será a partir del minuto } \\
75 \text {. }\end{array}$ & 19,11 & 210,21 & 401,31 & 535,08 \\
\hline $\begin{array}{l}\text { Cuidado subsecuente, por día, por la evaluación y manejo de un paciente que } \\
\text { requiere al menos de dos de estos tres componentes: baja decisión médica. } \\
\text { Consejería y/o coordinación del cuidado Un problema enfocado en la historia; } \\
\text { Un problema enfocado en el examen físico; Requiere de una moderada decisión } \\
\text { médica. Consejería y/o Coordinación del cuidado con otros servicios, según la } \\
\text { naturaleza del problema(s) y las necesidades del paciente(s) o su familia(s). } \\
\text { Usualmente, el paciente está estable o mejorando. Tiempo } 25 \text { minutos con el } \\
\text { paciente y/o su familia(s) y cuidador. }\end{array}$ & 19,11 & 210,21 & 401,31 & 535,08 \\
\hline TOTAL & 743,06 & 3154,86 & 4166,79 & 5422,38 \\
\hline \multicolumn{5}{|l|}{ MEDICACIÓN } \\
\hline Paracetamol Intravenoso & 14,1 & 126,9 & 253,8 & \\
\hline Dexametazona & 0,4 & 1,2 & 2,4 & \\
\hline Azitromicina & 1,6 & 8 & & \\
\hline Enoxaparina & 19,22 & 115,32 & & \\
\hline TOTAL & 1465,76 & 5781,62 & 7420,5 & 9285,72 \\
\hline \multirow[t]{2}{*}{ Servicio privado completo $(+10 \%)$} & 146,58 & 578,16 & 742,05 & 928,57 \\
\hline & 1612,34 & 6359,78 & 8162,55 & 10214,29 \\
\hline IVA $12 \%$ & 193,48 & 763,17 & 979,51 & 1225,72 \\
\hline COSTO TOTAL PRIVADO & 1805,82 & 7122,96 & 9142,06 & 11440,01 \\
\hline
\end{tabular}

Sintomático grave representando el $6 \%$, costo por estancia hospitalaria por día 1722,87 USD en hospitales públicos y 2122,58 USD en hospitales privados, por tiempo de evolución de 14 días, por un costo de 10041,16 USD en hospitales públicos y 12370,71 USD en hospitales privados, por tiempo de evolución de 21 días, por un costo de 14916,14 USD en hospitales públicos y 18376,38 USD en hospitales privados, por un tiempo de evolución de 28 días, por un costo de 18855,79 USD en hospitales públicos y 23230,33 USD en hospitales privados.

Tabla 3

Tratamiento pacientes invasivos

\begin{tabular}{lrrrr}
\hline \multicolumn{1}{c}{ HOSPEDAJE } & DIA & $\mathbf{1 4}$ & $\mathbf{2 1}$ & $\mathbf{2 8}$ \\
\hline HABITACIÓN INDIVIDUAL. INSTITUCIONES SEGUNDO NIVEL & 55,68 & 779,52 & 1169,28 & 1559,04 \\
CUIDADO Y MANEJO DIARIO. INSTITUCIONES DE SEGUNDO NIVEL & 8,91 & 124,74 & 187,11 & 249,48 \\
CUIDADOS INTENSIVOS DE ADULTOS Y NINOS/NEONATOLOGÍA & 204,89 & 2868,46 & 4302,69 & 5736,92 \\
INSTITUCIONES DE SEGUNDO NIVEL & 100,5 & 201 & \\
ULTRASONIDO ENDOSCÓPICO & 46,9 & & \\
DERECHOS DE SALA INST. SEGUNDO NIVEL & & & \\
PROCEDIMIENTOS DE MONITOREO & 0,54 & 7,56 & 11,34 & 15,12 \\
CONTROL DE PRESIÓN ARTERIAL & & &
\end{tabular}


Tabla 3

Tratamiento pacientes invasivos (continuación)

\begin{tabular}{|c|c|c|c|c|}
\hline HOSPEDAJE & DIA & 14 & 21 & 28 \\
\hline CONTROL DE SIGNOS VITALES & 1,34 & 18,76 & 28,14 & 37,52 \\
\hline INYECCIÓN INTRAMUSCULAR & 0,74 & 10,36 & 15,54 & 20,72 \\
\hline INYECCIÓN INTRAVENOSA & 0,94 & 13,16 & 19,74 & 26,32 \\
\hline CONTROL DE GLUCOSA CON TIRILLA & 0,8 & 11,2 & 16,8 & 22,4 \\
\hline CAMBIO SONDA VESICAL & 2,81 & 39,34 & 59,01 & 78,68 \\
\hline ADMINISTRACIÓN DE SOLUCIONES INTRAVENOSAS & 0,8 & 11,2 & 16,8 & 22,4 \\
\hline INYECCIONES SUBCUTÁNEAS & 0,74 & 10,36 & 15,54 & 20,72 \\
\hline Electrocardiograma, 12 derivaciones, de rutina, con interpretación y reporte. & 23,94 & 335,16 & 502,74 & 670,32 \\
\hline LABORATORIO CLINICO & TOMA & & & \\
\hline HIV $1+2$ & 8,38 & & & \\
\hline PCR CUANTITATIVO ULTRASENSIBLE & 9,44 & 18,88 & 37,76 & 75,52 \\
\hline CORTISOL & 14,1 & & & \\
\hline PROCALCITONINA LAB. CLINICO & 28,5 & & & 28,5 \\
\hline BIOMETRIA HEMATICA+VSG & 4,16 & 8,32 & 16,64 & 33,28 \\
\hline CALCULO DE PLAQUETAS & 3,04 & 6,08 & 12,16 & \\
\hline CONTAJE DE RETICULOCITOS & 3,35 & & & \\
\hline DIMERO-D & 33,47 & 66,94 & 133,88 & 267,76 \\
\hline FERRITINA & 9,13 & 18,26 & 36,52 & \\
\hline FIBRINOGENO & 8,51 & 17,02 & 34,04 & \\
\hline TIEMPO DE PROTROMBINA (TP) & 3,6 & 7,2 & 14,4 & 28,8 \\
\hline TIEMPO DE TROMBOPLASTINA (TTP) & 3,6 & 7,2 & 14,4 & 28,8 \\
\hline CREATININA & 3,48 & 6,96 & 13,92 & 27,84 \\
\hline ELECTROLITOS NA- K - CL EN SUERO O SANGRE TOTAL & 6,09 & 12,18 & 24,36 & 48,72 \\
\hline FOSFATASA-ALKALINA & 3,23 & 6,46 & & \\
\hline GLUCOSA & 1,93 & 3,86 & 7,72 & 15,44 \\
\hline LDH (DESHIDROGENASA LACTICA) & 3,42 & 6,84 & 13,68 & 27,36 \\
\hline NITROGENO UREICO (BUN) /UREA & 2,42 & 4,84 & 9,68 & \\
\hline TRIGLICERIDOS & 2,55 & 5,1 & & \\
\hline TROPONINA T & 17,7 & & & \\
\hline CK-MB & 14,35 & & & \\
\hline $\mathrm{CPK}$ & 8,07 & & & \\
\hline EMO (UROANALISIS DE RUTINA) & 3,23 & 6,46 & & \\
\hline COVID -19 PRUEBA CUANTITATIVA & 43,38 & 86,76 & 130,14 & 173,52 \\
\hline COVID - 19 RT-PCR & 120 & 240 & 360 & \\
\hline FT3 & 4,97 & & & \\
\hline FT4 & 4,97 & & & \\
\hline TIROGLOBULINA & 17,26 & & & \\
\hline ACIDO URICO & 2,98 & 5,96 & 11,92 & 23,84 \\
\hline ALT (SGPT) & 4,53 & 9,06 & 18,12 & \\
\hline AST (SGOT) & 2,17 & 4,34 & 8,68 & \\
\hline GASOMETRIA & 10,49 & 146,86 & 220,29 & 367,15 \\
\hline IMAGENOLOGIA & & & & \\
\hline
\end{tabular}


Tabla 3

Tratamiento pacientes invasivos (continuación)

\begin{tabular}{|c|c|c|c|c|}
\hline HOSPEDAJE & DIA & 14 & 21 & 28 \\
\hline EXAMEN RADIOLÓGICO, TÓRAX; POSICIÓN ÚNICA, FRONTAL & 16,46 & 32,92 & 49,38 & \\
\hline $\begin{array}{l}\text { TOMOGRAFÍA AXIAL COMPUTADORIZADA, TÓRAX; SIN MATERIAL DE } \\
\text { CONTRASTE }\end{array}$ & 72,16 & 144,32 & 288,64 & 577,28 \\
\hline ANGIOTAC TORÁCICA $(*)(* *)$ & 107,5 & & 215 & \\
\hline $\begin{array}{l}\text { TOMOGRAFÍA AXIAL COMPUTADORIZADA DE CABEZA O CEREBRO; SIN } \\
\text { MATERIAL DE CONTRASTE }(* *)\end{array}$ & & & 100,73 & \\
\hline ECO TRANSESOFAGICO $(*)(* *)$ & & 56,52 & 113,04 & \\
\hline \multicolumn{5}{|l|}{ PROCEDIMIENTOS DE REHABILITACIÓN } \\
\hline TERAPIA RESPIRATORIA (COBRAR POR SEPARADO USO DE OXÍGENO) & 5,9 & 165,2 & 247,8 & 330,4 \\
\hline \multicolumn{5}{|l|}{ HONORARIOS MEDICOS } \\
\hline CUIDADOS INTENSIVOS ENTRE LOS 30 PRIMEROS MINUTOS & 61,74 & 185,22 & & \\
\hline VALOR POSTERIOR A LAS 72 HORAS & 30,87 & 339,57 & 555,66 & 771,75 \\
\hline $\begin{array}{l}\text { Cuidado inicial, por día, por la evaluación y manejo de un paciente, que requiere de } \\
\text { esos tres componentes: } 1 \text {. Historia clínica detallada y comprensible } 2 .- \text { En examen } \\
\text { físico detallado } 3 \text {. Decisión médica sencilla y de alta complejidad. Consultoría y/o } \\
\text { Coordinación del cuidado con otros servicios, de acuerdo a las necesidades del } \\
\text { paciente(s) y/o de su familia. Usualmente, el problema(s) requiere de admisión de alta } \\
\text { severidad. Tiempo } 45 \text { min. con el paciente y/o familiares o cuidador }\end{array}$ & 29,4 & & & \\
\hline Anestesia complicada por la utilización de hipotensión controlada & 7,5 & 105 & 157,5 & 210 \\
\hline $\begin{array}{l}\text { Asistencia y manejo de ventilación. Iniciación de ventiladores preestablecidos de } \\
\text { presión o volumen para respiración asistida o controlada; paciente hospitalizado primer } \\
\text { día. }\end{array}$ & 20,4 & & & \\
\hline $\begin{array}{l}\text { Asistencia y manejo de ventilación. Iniciación de ventiladores preestablecidos de } \\
\text { presión o volumen para respiración asistida o controlada; cada día subsecuente en el } \\
\text { hospital }\end{array}$ & 14,96 & 209,44 & 314,16 & 418,88 \\
\hline $\begin{array}{l}\text { Colocación selectiva de catéter en sistema arterial, ramas torácicas y braquiocefálicas } \\
\text { iniciales de segundo orden, dentro de una familia vascular. }\end{array}$ & 120,23 & 360,69 & 480,92 & 601,15 \\
\hline HEMODIALISIS SIN REUSO DE FILTRO & 112 & & & 224 \\
\hline MEDICACIÓN & \multicolumn{2}{|c|}{ Valor unitario } & & \\
\hline EPRINEFRINA c/u & 2,24 & 31,36 & 47,04 & 62,72 \\
\hline Midazolam & 76,6 & 1072,4 & 1608,6 & 2144,8 \\
\hline Fentanil & 3,5 & 49 & 73,5 & 98 \\
\hline Propofol & 49,1 & 687,4 & 1031,1 & 1374,8 \\
\hline Rocuronio & 9,03 & 126,42 & 189,63 & 252,84 \\
\hline Lagrimas Artificiales & 2,1 & 4,2 & 8,4 & 12,6 \\
\hline Enoxaparina c/u & 1,2 & 16,8 & 25,2 & 33,6 \\
\hline Dexametazona & 0,4 & 2,4 & & \\
\hline Enjuague Bucal & 1,05 & 2,1 & & \\
\hline Tubo Endotraquial & 4 & 8 & 16 & 20 \\
\hline Paracetamol Intravenoso & 42,9 & 257,4 & 343,2 & \\
\hline oxigeno litro & 75,6 & 1058,4 & 1587,6 & 2116,8 \\
\hline TOTAL & 1722,9 & 10041,2 & 14916,1 & 18855,8 \\
\hline \multirow[t]{2}{*}{ VALOR PRIVADO $(+10 \%)$} & 172,29 & 1004,12 & 1491,61 & 1885,58 \\
\hline & 1895,2 & 11045,3 & 16407,8 & 20741,4 \\
\hline IVA $12 \%$ & 227,42 & 1325,43 & 1968,93 & 2488,96 \\
\hline TOTAL & 2122,6 & 12370,7 & 18376,7 & 23230,3 \\
\hline
\end{tabular}




\section{Discusión}

Para determinar los costos de atención se deben tomar en cuenta varios factores, entre ellos: atención primaria en salud, estancia hospitalaria, honorarios médicos (en instituciones privadas), medicamentos, insumos, servicios adicionales y áreas críticas con ventilación mecánica, calidad de atención.

Inca-Ruiz \& Inca-Leon, (2020), menciona que en comparación al inicio de la pandemia estos costos no influyeron en la atención; pese a ello durante el primer semestre de atención de la pandemia los casos de Covid-19 no fueron controlados.

La tasa de casos positivos de COVID-19 en Ecuador, de 10.94 por cada 100000 habitantes, supera la media a nivel mundial que es de 7.33 por cada 100 000. Los casos empiezan a ser más altos en el país a partir del décimo día de haberse reportado el primer caso. (p.7)

En comparación a los datos reales establecidos por el INEC en el Ecuador en junio del 2021, del total de la población el $19 \%$ fueron casos positivos moderados y graves (3’376.005) con diferentes tipos de tratamientos, y de los casos críticos que utilizaron área de terapia intensiva con tratamiento invasivos y que pese a ello fallecieron es el $7,22 \%$ (1’282.882) de la población hasta la actualidad (Instituto Nacional de Estadisticas y Censos, 2021).

Los costos de COVID-19 en el Ecuador y el mundo llegaron a ser sumamente altos en el inicio de la pandemia y en especial en los países de Latinoamérica por un sistema de salud deficiente en inversión estructural y de abastecimiento de equipos, insumos y medicamentos.

La directora de la Asociación Nacional de Clínicas y Hospitales Privados de Ecuador, Ana Delgado, dice que los costos que se originan en las clínicas y hospitales privados se deben a que "las Unidades de Cuidados Intensivos son áreas de alta complejidad que cuentan con diferentes especialistas, equipos de altos costos como los ventiladores mecánicos e insumos de consumo diario que aumentan los costos exponencialmente" además de ello; se señala que existen deudas hacia los hospitales privados por parte del estado lo que hizo que en algún momento fue insostenible la atención integral de pacientes Covid-19 derivados a la red complementaria, por lo cual se optó por atenciones de manera privada (Notimundo, 2021).

Ecuador fue uno de los países donde se registró el costo más alto de la prueba de COVID19 en Latinoamérica, el costo de una prueba de reacción en cadena de la polimerasa con transcripción inversa en tiempo real (RT-PCR) osciló entre USD 120 a USD 170 en los laboratorios autorizados por la Agencia de Aseguramiento de la Calidad de los Servicios de Salud y Medicina Pre-pagada (ACESS) y el Ministerio de Salud Pública (MSP) del Ecuador, los costos de insumos tuvieron una inflación exorbitante de precio, que no fueron regulados por la Agencia de Regulación Sanitaria (ARSA) durante el decreto de 
emergencia sanitaria establecida en el registro oficial del 12 de marzo del 2020 (Ministerio de Salud Pública, 2020).

En general el estado destina en total el 3,81\% del PIB anual, se produjo un incremento del 0,5\% para el año 2020 sin tomar en consideración el estado de emergencia sanitaria; pese a este incremento solo fue destinado el $2 \%$ para mejorar el sistema de salud, $12 \%$ para la adquisición de medicamentos, $26 \%$ para dispositivos médicos, $36 \%$ en pagos para personal de salud; existiendo un déficit del $11 \%$ de presupuesto para cubrir las necesidades hospitalarias del $19 \%$ de pacientes infectados de Covid-19, con sintomatología moderada a grave (El Universo, 2020).

De acuerdo con el presente estudio, se evidenció el costo real que se fue presentando durante la estancia hospitalaria en casos moderados a graves, considerando las medidas de aislamiento, paralización de productividad económica, las condiciones socio económicas; basándonos en el tarifario nacional de los servicios sanitarios; los costos hospitalarios incrementaron por a limitaciones de acceso a los sistemas de salud, tanto de la red integral pública de salud (RIPS) y la red complementaria. Muchos de los casos debieron ser hospitalizados (casos no invasivos); los costos en el servicio privado superaban el sueldo básico unificado establecido en el año 2020 de 400 USD (Ministerio del Trabajo, 2020).

En caso de pacientes graves hospitalizados, que requerían los servicios de Terapia Intensiva, se debe considerar que; la estancia hospitalaria, personal de salud, medicamentos, insumos, procedimientos, exámenes complementarios y dispositivos médicos, tuvieron valores elevados superiores a los 1000 USD diarios, muchos casos de hospitalización superaron los 28 días considerados en este estudio.

Es importante mencionar que el sistema de salud pública no estuvo preparado para suplir las necesidades de la emergencia sanitaria, presentando infraestructuras subutilizadas, presupuestos mal distribuidos, déficit de medicamentos e insumos para lo cual; una de las medidas principales es el desarrollo de controles estratégicos, vigilancia pública bajo fiscalización continua de un adecuado uso de presupuesto, adquisición de insumos, medicamentos, mantenimiento de equipos y recursos humanos acordes a cada establecimiento de salud.

Basados en modelos estructurados como el canadiense en materia de salud pública, es importante establecer medidas de control técnico, esto mejoraría la capacidad resolutiva y la descongestión del segundo y tercer nivel de atención médica, modelos de salud como el español, nos enseñan que una distribución adecuada para mejorar los sistemas preventivos, disminuyen considerablemente los ingresos hospitalarios y por ende el gasto público; con estas estrategias se podría mejorar el sistema sanitario al brindar mejores servicios de atención. 


\section{Conclusiones}

- Determinamos que los costos establecidos durante el primer semestre del 2020, en emergencia sanitaria no tuvieron control adecuado por las entidades reguladoras gubernamentales.

- Para atención hospitalaria fueron necesarios recursos económicos altos, que no fueron contemplados por los usuarios, los sistemas públicos de salud se encontraban deficientes y precarios para poder suplir las necesidades poblacionales.

- Basados en modelos internacionales de sistemas de salud con resultados eficaces en control económico, medidas estratégicas para mejorar continuamente los servicios de calidad, medidas preventivas con abastecimientos adecuados en la atención primaria podrán mejorar las condiciones sanitarias actuales en nuestro sistema de salud pública.

- Se expuso el sistema de salud con una limitación exorbitante de los servicios públicos por lo cual; la red complementaria y los establecimientos privados a pesar de estar preparados parcialmente no abastecieron la capacidad necesaria de atención de pacientes COVID-19.

\section{Referencias bibliográficas}

Bajaña, I. (mayo de 2020). INCIDENCIAS DEL COVID - 19 EN ECUADOR. Questión Periodismo/comunicación, $3, \quad 1 \quad-\quad 13 . \quad$ doi:DOI: https://doi.org/10.24215/16696581e321

Chauca, R. (abr. - jun. de 2021). La covid - 19 en Ecuador: fragilidad pólitica y precariedad de la salud pública. História, Ciências, Saude - Manguinhos, 28(2), $587-591$.

Cioti, M., Cicozzi, M., Terrinoni, A., Jiang, W. -C., Bin-Wang, C., \& Bernardini, S. (2020). The COVID 19 pandemic. Critical Reviews in Clinical Laboratory Sciences, 57(6), 365 - 388. doi:https://doi.org/10.1080/10408363.2020.1783198

El Universo. (23 de Marzo de 2020). Gobierno de Ecuador detalla los recursos asignados para Salud y emergencia sanitaria. Comunidad-El Universo.

Inca-Ruiz, G., \& Inca-Leon, A. (Abril de 2020). Evolución de la enfermedad por coronavirus (COVID 19) en Ecuador. La Ciencia al Serivicio de la Salud y Nutricion, $\quad 11(1) . \quad$ Obtenido de http://revistas.espoch.edu.ec/index.php/cssn/article/view/441/422

Instituto Nacional de Estadisticas y Censos. (Junio de 2021). INEC. Obtenido de Boletin Técnico de Camas y Egresos Hospitalarios, Junio 2021: https://www.ecuadorencifras.gob.ec/documentos/webinec/Estadisticas_Sociales/Camas_Egresos_Hospitalarios/Cam_Egre_Hos_2020 /Bolet\%C3\%ADn\%20t\%C3\%A9cnico\%20ECEH_2020.pdf 
Ministerio de Salud Pública. (2020). ACUERDO No 00126 - 2020. Quito: Registro Oficial Órgano de la República del Ecuador. Obtenido de https://www.registroficial.gob.ec/index.php/registro-oficial-web/

MINISTERIO DE SANIDAD. (26 de marzo de 2020). Ministerio de Sanidad de Barcelona. Obtenido de Centro de Coordinación de Alertas y Emergencias Sanitarias:

https://www.mscbs.gob.es/profesionales/saludPublica/ccayes/alertasActual/nCo v/documentos/20200326_ITCoronavirus.pdf

Ministerio del Trabajo. (2020). ACUERDO MINISTERIAL Nro. MDT-2020- 282 . Quito.

Molina, N., \& Mejias, M. (jul.-sep. de 2020). Impacto social de la COVID 19 en Brasil y Ecuador: donde la realidad supera las estadísticas. Edumecentro, 12(3), 277 - 283. Obtenido de http://scielo.sld.cu/scielo.php?pid=S2077$28742020000300277 \&$ script=sci_arttext\&tlng=pt

Notimundo. (Enero de 2021). FM Mundo. Obtenido de Notimundo al Día: https://notimundo.com.ec/clinicas-y-hospitales-privados-registran-incrementoen-ocupacion-de-camas/

Organización Mundial de la Salud. (2020). Determinantes de la COVID 19 . OMS .

Organización Panamericana de Salud / Organización Mundial de la Salud. (14 de febrero de 2020). Actualización Epidemiológica Nuevo Coronavirus (COVID-19). (OPS/OMS, Ed.)

Ortiz - Prado, E., \& Fernandez-Naranjo, R. (2020). Impacto de la COVID-19 en el Ecuador: De Los Datos Inexactos a Las Muertes en Exceso. Revista Ecuatoriana de Neurología, 29(1). doi:10.46997/revecuatneurol29200008

Programa de las Naciones Unidas para el Desarrollo. (20 de marzo de 2020). Un marco conceptual para analizar el impacto económico del COVID-19 y sus repercusiones en las políticas. PNUD América Latina y el Caribe.

Sedano-Chiroque, F., Rojas-Miliano, C., \& Vela-Ruiz, J. (2020). COVID 19 DESDE LA PERSPECTIVA DE LA PREVENCIÓN PRIMARIA. Facultad de Medicina Humana URP, 20(3), 494 - 501. doi:DOI 10.25176/RFMH.v20i3.3031

Velez-Paez, J., Montalvo-Villagomez, M., Jara-Gonzales, F., Moscoso-Aguayo, S., Tercero-Martinez, W., Saltos-Iñigues, L., . . Dawaher, J. (Enero-Abril de 2021). Guía de manejo de pacientes COVID19 en terapia intensiva - Hospital Pablo Arturo Suárez. Revista Cienca UNEMI, 14(35), 92-107. doi:https://doi.org/10.29076/issn.2528-7737vol14iss35.2021pp92-107p 


\section{PARA CITAR EL ARTÍCULO INDEXADO.}

López Ullauri, V. G., Chasipanta Avalos, M. E., Campoverde Ávila, A. E., \& Pavón Rosero, L. E. (2021). Impacto por COVID-19 en Ecuador y planteamiento de una propuesta de política pública de prevención. Anatomía Digital, 4(4), 97-111. https://doi.org/10.33262/anatomiadigital.v4i4.1911

\section{LCiencia}

El artículo que se publica es de exclusiva responsabilidad de los autores y no necesariamente reflejan el pensamiento de la Revista Anatomía Digital.

El artículo queda en propiedad de la revista y, por tanto, su publicación parcial y/o total en otro medio tiene que ser autorizado por el director de la Revista Anatomía Digital.
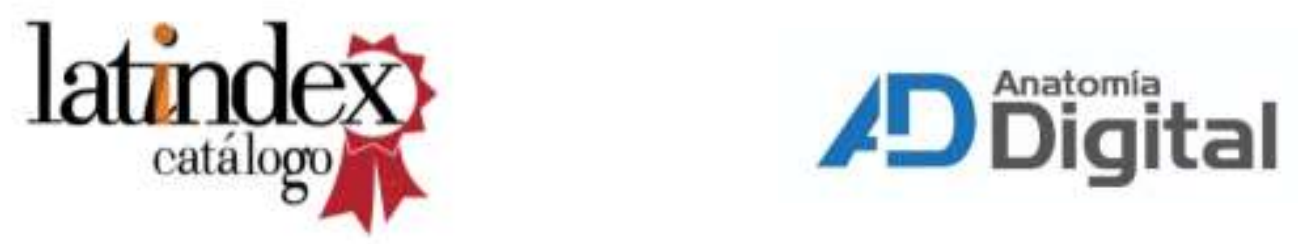